\title{
Transforming Roles: Canadian Academic Librarians Embedded in Faculty Research Projects
}

\author{
Shailoo Bedi and Christine Walde*
}

\begin{abstract}
Academic librarians have always played an important role in providing research services and research-skills development to faculty in higher education. But that role is evolving to include the academic librarian as a unique and necessary research partner, practitioner, and participant in collaborative, grant-funded research projects. This article describes how a selected sample of Canadian academic librarians became embedded in faculty research projects and describes their experiences of participating in research teams. Conducted as a series of semistructured interviews, this qualitative study illustrates the emerging opportunities and challenges of the librarian-researcher role and how it is transforming the Canadian university library.
\end{abstract}

\section{Introduction and Purpose of Study}

With the advent of new technologies and the importance of new knowledge economies within higher education, the role of the academic librarian is changing. As collections become increasingly patron-driven, and libraries share evolving service models, traditional duties such as cataloguing, reference, and collection development are not necessarily core duties of all academic librarians. ${ }^{1}$ As a result of this shift, librarians have been gaining - and demonstrating - increased value within higher education as it relates to the life cycle of research, learning, and teaching.

Clearly, competition is increasing within higher education, and individual institutions throughout Canada and the United States strive to distinguish themselves through their research and innovation. ${ }^{2}$ To demonstrate measurable return on investment, faculty researchers are striving to diversify their research teams to gain increased success in grant competitions and remain current in their field of research. Increasingly, Canadian academic librarians are recognizing the changes in the landscape and the opportunities available to them to become embedded in grant-funded faculty research teams.

As academic librarians, we were inspired by a desire to contribute to a larger discussion around trends in research in Canadian academic librarianship through an exploratory study that examines the experience and learning of Canadian academic librarians who were embedded in faculty research and to show how these experiences

* Shailoo Bedi is Director, Academic Commons and Strategic Assessment in University of Victoria Libraries, Academic Commons at University of Victoria; e-mail: shailoo@uvic.ca. Christine Walde is Grants and Awards Librarian in University of Victoria Libraries, University Librarian's Office at University of Victoria; e-mail: cwalde@uvic.ca. 
are influencing the transformation of the academic librarian role in Canada. Unlike our American colleagues, many Canadian academic librarians are not required to do research for tenure and promotion; however, there is an expectation among many that they do research, not only for professional development, but to contribute to the profession. In many ways, our study is an attempt to bridge the current literature that exists around the researcher role of academic librarians but within a Canadian context. We decided that focusing on the Canadian context was important because it relates to our working environment, and we recognized that little attention is given to the researcher role of librarians in Canada. The Canadian Association of Research Libraries (CARLABRC) has been leading the discussion of changing roles among library leaders and university librarians for the past decade. CARL institutions have been instrumental in supporting the researcher role among academic librarians through programs such as the annual Librarians' Research Institute and the CARL Research in Librarianship Grant. Given these professional support mechanisms, we felt that CARL librarians were the most suitable candidates for our study and solicited CARL university librarians to recommend individual librarians, from a range of disciplines across the academy, who fit the profile of an embedded librarian within a faculty research project.

As our literature review will highlight, there are several articles that discuss the role of the librarian as researcher. However, most of the discussion focuses on quantitative studies and generalizable data. We identified a gap in the literature from a qualitative approach regarding librarians' personal and professional experiences as researchers embedded in faculty research projects from a Canadian perspective. Since we were unable to locate further data on this topic in the literature, we invited academic librarians to participate in our study using qualitative inquiry methods to capture the experiences and learning of Canadian academic librarians embedded in collaborative research projects with faculty members.

Since our research question was to explore the experiences of Canadian academic librarians embedded as collaborators in faculty research projects, we recognized that a qualitative study was the most appropriate methodology to gather the individual voices of Canadian academic librarians, who have not been recorded or given an opportunity to share their experiences in the research process. While faculty and their findings are routinely celebrated, the librarians who have been working steadfastly from the sidelines on a variety of research projects - either off the side of their desk or as a part of their job or research interest-have often not been heard. With the increasing importance of Open Access and data management, the role of the librarian has become instrumental to research teams.

As librarians, we wanted to demystify stigmas that prevent librarians from doing research and to inspire other librarians to do research. Working in collaborative research teams, academic librarians have an important and pivotal role to play, not only within the pursuit and practice of LIS (library information science) research, but also as contributors to knowledge within the academic community. Through learning more about our participants' experiences and their growth and development as researchers - in essence, by telling their stories - we hope to provide meaningful data that will help to define, develop, and lead to further investment in the researcher role within Canadian academic librarianship.

\section{Literature Review}

An investigation of the existing literature on the topic of academic librarians and research revealed several articles. Most of these are focused on quantitative studies related to the publication patterns of librarians for promotion and tenure and are primarily based on U.S. academic libraries. ${ }^{3}$ In addition, several articles have been written about 
the types of institutional supports available for librarians to conduct research, such as study leaves, grants, and general release time, and how they contribute to the research output of librarians. ${ }^{4}$ This group also includes studies that have surveyed library directors on their perspectives of academic librarians' role as researchers. ${ }^{5}$

Qualitative studies on the topic of academic librarians as researchers are also prevalent but are primarily focused on the American context. In Canada, limited literature exists on Canadian academic librarian experiences with research in faculty collaborations. Although literature does exist on the emerging role of librarians as researchers, few are focused on collaborations with faculty that may involve the librarian as coinvestigators-especially on research topics that are not specific to library sciences. Unlike the American academic librarian model, in Canada few academic libraries offer tenure to academic librarians. Thus there is little to no formal structure of research and publication as part of the promotion and tenure of academic librarians, and the overall practice varies from institution to institution. ${ }^{6}$ Scholarly activities and publications are not a significant factor in Canadian academic librarians' formal promotion and evaluation as they are at many American academic libraries, where the "publish or perish" model plays a more integral role in the overall evaluation process. In addition to this, academic librarians with nonfaculty status in Canada have fewer opportunities to secure research grant funds, thus making them somewhat less attractive as potential collaborative researchers with faculty.

Our review did identify one article that discusses librarians as researchers. In their 2002 quantitative study, Powell, Baker, and Mika ${ }^{7}$ strongly emphasize the need for librarians to engage in the empirical research process, stating that "research is not a process that is the responsibility of others; research is a way of knowing, a way of making better practical decisions that is the responsibility of each of us." ${ }^{8}$ They point out that librarians have a fundamental role in the research process not just to produce empirical research but as a way to learn further about the research process and ultimately to make better decisions on services we provide through reference, instruction, and collection.

\section{Research and Librarians: A Recent History}

In 2007, Fox's study of time spent on scholarly activities by librarians was a groundbreaking article for its Canadian content. ${ }^{9}$ Using a quantitative approach, Fox surveyed academic librarians at research universities who are members of CARL. The primary focus of his study was to examine how much time academic librarians spent on scholarly activities while balancing significant professional assignments related to reference, collection, and instruction-oriented tasks. ${ }^{10}$ Interest in the topic of research among Canadian librarians was clearly strong, as Fox yielded a 49.4 percent response rate. His results concluded that there is a perceived lack of time for Canadian academic librarians to engage in research and scholarship. Among his recommendations, Fox advocates strongly for librarians to take advantage of their study leave provisions.

One of the early emergences of the term "practitioner-researcher" as applied to librarians is found in Watson-Boone's article "Academic Librarians as Practitioner Researchers in College and Research Libraries."11 In this study, Watson-Boone investigates the output of research articles by academic librarians in The Journal of Academic Librarianship over a ten-year period and identifies the predominant research methods used by academic librarians. Watson-Boone finds that 43 percent of articles published in LIS literature is produced by academic librarians and the rest by professors of LIS. Thus she concludes that academic librarians "are members of a growing group within the knowledge base of professionals now being called 'practitioner- researchers.'"12 She identifies the main research methods used by academic librarians to be action research, case study, program evaluation, experimental research, and survey research. 
In a more recent article entitled "Academic Librarian Research: A Survey of Attitudes, Involvement, and Perceived Capabilities," the authors Kennedy and Brancolini were motivated by a desire to help academic librarians improve their research skills and increase the quantity and quality of their research. ${ }^{13}$ Their study asked, "How does a practitioner-researcher librarian develop the necessary skills to conduct research and produce reliable and valid research?" To investigate this question, the authors conducted a survey from which they concluded that, although the majority of those surveyed were frequent readers of academic articles, most librarians lacked the confidence to conduct primary research. The authors found that there was a correlation between academic librarians who conducted research in their professional capacities and the amount of research training they had received either through their MLIS or post-MLIS degree. Kennedy and Brancolini advocate strongly in their conclusion for more research institutes where librarians can study research design. Following their own recommendation, they co-designed a summer institute for research design in librarianship.

\section{The Embedded Librarian}

In addition to the academic discussion around librarians as research practitioners, we also examined literature about the "embedded librarian." The term or label "embedded librarian" has been around for some time now and is often used to define librarians who work "outside" the traditional walls of the library. Shumaker, ${ }^{14}$ who dates the use of the term to the 1970s, defines embedded librarianship as "a distinctive innovation that moves the librarians out of libraries [and] emphasizes the importance of forming a strong working relationship between the librarian and a group or team of people who need the librarian's information expertise. ${ }^{\prime 15}$ In reviewing specific literature on embedded librarians in higher education, we found a number of articles about librarians who engage in the teaching and learning process by becoming embedded in curriculum design or co-teaching activities with faculty. ${ }^{16}$ This model of embedded librarianship has been active on campuses and is most prevalent within professional disciplines like medicine and law. In these models, the embedded librarian facilitates student learning, extending the traditional librarian role of information-literacy instruction to becoming an active participant in the planning, development, and delivery of course-specific or discipline-specific curriculum. The key feature of embedded librarianship is the collaboration that exists between the librarian and the faculty member(s). ${ }^{17}$

However, with the emergence of the librarian as researcher, we identified more articles related to librarians embedded not just within instructional design, but in the research context. ${ }^{18}$ In models where academic librarians are embedded within a research project, Carlson and Kneale explain that "a librarian works with research more 'upstream' in the research process rather than just with the products produced at the end of the research life cycle." ${ }^{19}$ More often than not, librarians have had more of a role in the literature-search process with faculty research projects as well as advising on appropriate places for publication.

Although there is clearly a robust and active discourse in the literature on librarians as researchers and librarians embedded in the research process, there has been little discussion of the actual experiences and learning gained by academic librarians who are actively engaging as research partners in faculty research projects. This gap leads us to our research project.

\section{Research Question}

As previously mentioned, we were guided by a deep curiosity to explore the experiences and learning of Canadian academic librarians who were embedded in faculty 
research and to show how these experiences are influencing the transforming roles of academic librarians. After we identified the gap in the literature, we had not just one question, but many. We wanted to explore not only how academic librarians became embedded in faculty research, but whether they had studied research methods as part of their LIS education and whether or not they felt they had the adequate education, training, and research skills to undertake the role of research practitioner. We also wanted to know what their specific roles were during their research projects, what they felt their strengths were, what they had learned, and how their work as researchers was perceived by their colleagues and institutions. Therefore, our guiding research question became "In what ways have Canadian academic librarians become embedded in faculty research projects, and how have their roles been transformed by their experience as researchers?"

\section{Method}

The purpose of this study is to explore and highlight the experience and learning of academic librarians embedded in faculty research projects. We also hope to give voice to their experiences and to contribute to the discussion on how librarian roles are being transformed. Thus, given that the nature of this inquiry is about understanding a phenomenon from the perspective of our research participants, it falls within the qualitative research paradigm. Rubin and Rubin ${ }^{20}$ support this claim, noting that qualitative inquiry is a way to learn about the thoughts and feelings of others. Creswell confirms this, stating:

Qualitative research is best suited to address a research problem in which you do not know the variable and need to explore. The literature might yield little information about the phenomenon of study, and you need to learn more from participants through exploration. [Thus] a central phenomenon is the key concept, idea, or process studied in qualitative research. ${ }^{21}$

We launched our study in the summer of 2013 after we received approval from the University of Victoria's Human Research Ethics Board. The participants were composed of a group of academic librarians working at CARL-member universities who were embedded as partners or collaborators in a primary research investigation. We targeted CARL libraries because member libraries are the most research-focused in Canada. Given this emphasis on research focus and research intensity, we made the assumption that librarians from these institutions would clearly meet our criteria. Another advantage of targeting CARL members was that they are spread across Canada.

To recruit CARL academic librarians who had been specifically embedded in faculty research projects, we sent introduction letters to university librarians requesting that they nominate an academic librarian who fell within our research criteria. Given that university librarians were recommending a librarian or librarians from their institution, we could only offer limited anonymity to participants but could ensure confidentiality regarding the experiences they shared with us. We conducted individual interviews with each participant. Interviews are often used in qualitative research studies to explore things that cannot be directly observed. ${ }^{22}$ We used semi-structured interviews rather than in-depth interviewing. This approach allowed us as interviewers to explore and probe with related questions as experiences and reflections were revealed by the participants. In addition, the semi-structured interview format allowed us to elicit information about the participants' views and experiences and allowed them to talk about what was important to them regarding the issues under discussion. Thus our use of interviewing allowed us as the researchers to enter into each participant's 
experience and learn from their perspective. The interview questions were supplied to each participant prior to the interview to allow for transparency of the questions and to allow participants time to reflect on and consider their responses.

Our set of questions specifically examined the role of academic librarians embedded in faculty research projects. We were not interested in gathering facts to measure certain patterns, but rather to gather the stories and experiences of librarians to understand the meaning they placed on their experience and, ultimately, the learning from their experience. We asked all participants the same sixteen open-ended questions. Overall, we hoped that this approach would help us to identify both common and unique experiences of librarians embedded into faculty research projects and be able to provide recommendations from which other librarians who are interested in exploring their roles as researchers might find inspiration. We received eighteen referrals and we then matched our list of potential participants to our criteria and ended up with eight research participants.

In the fall of 2013, we interviewed our eight participants, all of whom were academic librarians from CARL libraries across Canada. Of our sample, 6 identified as being female and 2 as male; 5 were subject librarians, from a variety of disciplines in both the sciences and humanities, while 2 were library administrators and 1 was a systems librarian. Some participants were involved in multiple research projects at the time of our interviews: 6 participants had acted in the capacity as either collaborators or coinvestigators, while 3 had been primary investigators.

Seven interviews were conducted using teleconference equipment, and one was conducted in person. The interviews were recorded and ranged from 45 to 90 minutes in length. Later, the interviews were transcribed verbatim by a research assistant. We continually reviewed and compared the interview data throughout the process to discover emerging themes from each participant interviewed. After coding the data, themes were identified and patterns drawn between codes. These themes and patterns revealed a common set of experiences and learning as well as unique experiences among the research participants.

\section{Findings}

In addition to capturing the voices and stories of Canadian academic librarians, the goal of our research was to explore how they became embedded in faculty research project teams and in what capacity, and to gather information about their experiences and learning from being embedded in a faculty research project. Not only was there a complexity to each librarian's answers, but each of their stories revealed an intellectually rigorous and objective approach to research and their participation in research teams. Several of the librarians we interviewed played a traditional supporting role, in that their main role was with literature searches and identifying the most relevant sources for the research being conducted, and were seen as equal members of these research teams, valued for their unique academic contributions. This resulted in greater engagement with their own research and the profession of librarianship, and a more meaningful and lasting relationship with faculty, students, and colleagues. Ultimately, this experience led to a total transformation of their everyday work as librarians.

The ways in which our participants became embedded in faculty research teams were multi-faceted. While some of the results are indicative of areas of responsibility within their day-to-day jobs, there were often areas of overlap between the avenues of participation, which is not unusual given the interdisciplinary nature of their research involvement. 


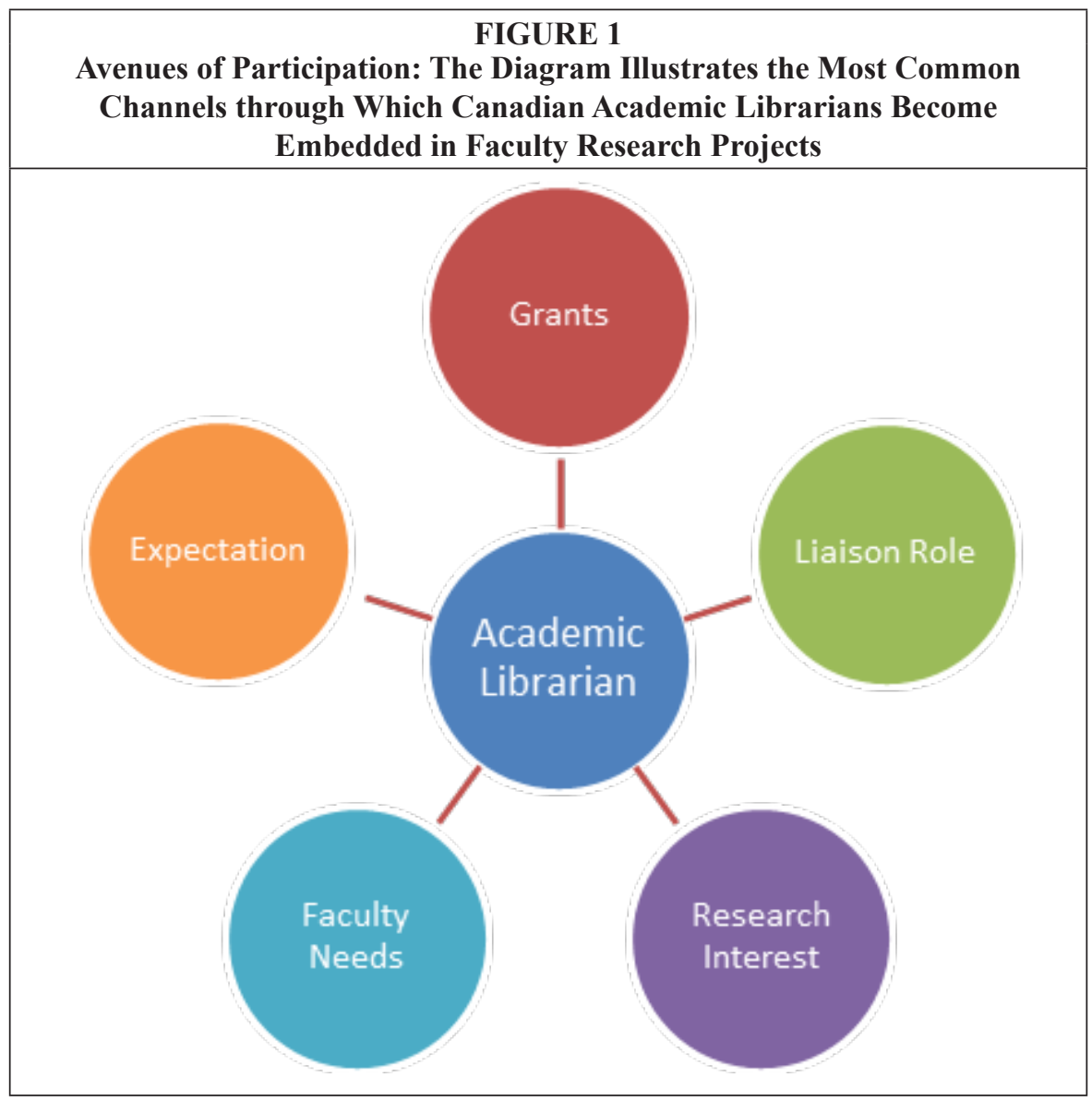

\section{Grants}

The majority of our interview participants became involved in faculty research projects as part of a proposal for grant funding from one of the Canadian Tri-Council funding agencies: Social Sciences and Humanities Research Council (SSHRC), Natural Sciences and Engineering Research Council (NSERC), or Canadian Institutes of Health Research (CIHR). Librarians were involved as collaborators, investigators, project managers, and - in one case-a principal investigator.

As national funding agencies increasingly recognize the value and importance of forming diverse research teams, librarians are seen as an important component of the research team, particularly with the emergence of requisite Open Access policies as well as policies governing research data management. According to more than one participant, they initially became involved through their liaison activities, which evolved into grant writing to support the research:

I was sort of put on the project as the library liaison and helped with writing the grant...That's actually a significant role for me, helping with the grant writing and overseeing and coordinating the library's role in various projects. (Participant F) 
Many of our participants pointed to the importance of being involved in the grant application process, echoing Arlitsch's statement that "grants can make the difference between a staid career and one that is marked by the kind of innovation and development that a cash infusion can catalyze." ${ }^{23}$ More important, perhaps, is the understanding that being involved in a large research grant helps to validate and support the role of the academic librarian as a researcher who can contribute beyond service-based models.

I think it's important...in a research university to show that you are one of them... You contribute to society, you contribute to community, you contribute to the academic research community. I think that's very important. (Participant E)

\title{
Liaison Role
}

Many of the librarians from our research study became embedded in faculty research projects through relationships they developed as part of their liaison role:

\begin{abstract}
About a year ago, when one of the faculty members was looking at refreshing [an online bibliography] ...she got in touch with me... She also used to be the library rep for the department, so she and I had a previous relationship around other issues... The project sort of grew to a whole other separate project, as more of a digital humanities resource. (Participant G)
\end{abstract}

Just as grants offer academic librarians an important opportunity to become embedded in a research project, so too does the liaison role, which allows faculty researchers to draw upon the subject expertise and skill sets of librarians related to their discipline. This was a prevalent role for our participants. As Participant C noted ironically, "I've ended up actually being a co-applicant on SSHRC grants as a result of ...basically answering a reference question." As the following quote also illustrates, the liaison role of the librarian evolved as a result of their involvement, which allowed them to meritoriously develop their connection to the faculty researcher and "to know what they're doing and ...get into their space without being a threatening person." (Participant G) Our findings conclusively support the value of the liaison role as an effective model of engagement, ensuring librarians' participation in research funded projects as trusted team members.

\section{Research Interest}

Almost all of our participants expressed a deep research interest, making this an important finding of our study. Our participants became embedded in faculty research projects because they were driven by the same questions as faculty researchers and had their own vested research interests within the same discipline as the faculty researcher. As participant A pointed out, "I'm attracted by their topics. It is the same as my personal curiosity because I am the subject librarian in the same field." Participant $\mathrm{H}$ mentioned that originally she was not considered as a co-investigator by a faculty member in cultural studies but was approached to help build an archive. But through consultation and discussion, it became clear that her experience in critical theory and her desire not only to build the archive but "to be able to theorize it" would be valuable to the project. As a result, she explained, the faculty member "added me as co-investigator on the SSHRC grant [since] our research objectives were mutually constitutive."

Participants were also interested in research because they wanted to learn more about the process of conducting research, confirming a key trait well-documented in the study of research librarians at the University of Saskatchewan, who "wanted 
to increase their knowledge about research"24 through their involvement. For our participants, being embedded in a faculty research project was a way to expand into new areas of research while pursuing opportunities related to project leadership. This translated into the evolving professional value librarians place on understanding more about research and the research process:

I think the value for me as a professional librarian is getting a better understanding of how research works in different disciplines [and]...getting a different perspective on the organization and culture of research groups in different areas...It's being challenged to dig deeper into the literature in the new area or an area that I would not normally be playing around in...It's skills building and exposure to different environments, different literature, different models of collaboration. (Participant F)

\section{Faculty Needs}

Librarians have an extraordinary competency for content expertise, particularly in an interdisciplinary capacity. A neutral facilitator among academic units, the librarian often brings an important perspective to the research team that no one else can provide. Librarians have a unique and extensive range of skill sets to meet a diverse range of faculty needs. As Participant G pointed out, she was originally approached by a faculty member to update an outdated bibliography: "She just wanted new titles added to the bibliography, but as we were talking, and as I was telling her about the sorts of material and sources that the library is now involved in, the project sort of grew quite a bit to a whole other project." Eventually, the librarian and faculty member created what Participant $G$ described as "a digital humanities resource...utilizing some of the advances in ...scanning technology...to build a database" that connected all of the resources on the research project topic.

For librarians and faculty, "a definite asymmetry between the two groups in terms of their perceptions ${ }^{\prime 25}$ may still persist, but our findings suggest otherwise. Far from being disconnected, faculty inherently understand the role of librarians and their ability to fulfill a number of research objectives. As Participant B stated, "These research teams needed a librarian ... and needed the skills a librarian could bring to the table." Faculty are increasingly beginning to understand these skills, and this is particularly true as Tri-Council policies on Open Access evolves across the disciplines. Many researchers are not only looking to the library and its librarians to disseminate and make their findings available to their mutual communities, but also to provide a safe repository for their data. As our participants note, the librarian's content expertise, along with their technical skills and knowledge of the rapidly changing information environment, are desirable competencies that add validity and academic integrity to faculty research projects.

Other people knew the subject matter...but they didn't have the technical expertise that I had, and I was only beginning being a data librarian at that point, so I didn't feel as though I knew as much about some of the quantitative work. But it became obvious fairly quickly that I knew more than a lot of the other people on the team. (Participant C)

\section{Mandatory}

In our study, we found that the majority of librarians, while not officially required to do research for tenure and promotion, understood that, as CARL librarians, they were expected to conduct research and fulfill a number of core competencies including the 
ability to "be knowledgeable of, and commit to, ongoing research and professional development." 26 For all of our participants, being embedded in a faculty research project was a meaningful way to fulfill their research contributions through a natural evolution of the collaborative process they had initiated in their liaison role:

There is an expectation to be involved in [evidence]-based practice and research... The liaison model is really strong, so being involved in research with... my liaison group makes a lot of sense. (Participant D)

If librarians lack the confidence to conduct the research that is expected of them, ${ }^{27}$ partnering with a faculty member allows them to gain improved competencies in research methods and research design, while simultaneously enhancing their skills as librarians and achieving greater capacity in their ability to perform their own research. Our findings indicate that librarians hold a unique position within the academy since they are both neutral and interdisciplinary, and can help "de-silo" academic units. And whether it is mandatory or not, most of our participants expressed pride in having proven that they too, as academic librarians, could conduct research:

I think you have to practice what you preach, you know, so I have to be a researcher myself.... If you're a researcher at a research university, that's what makes the university. (Participant E)

\section{Analysis of Findings}

Derived from the results of our interview questions, our data identified that most of our interviewees were independent, lifelong learners with a willingness to gain new experiences in LIS and to be adaptive across a range of skills in other research disciplines. Furthermore, they were all (to some degree) creative risk-takers, as well as determined, hard-working, and positive thinkers.

\section{Lifelong Learning}

Most of the librarians in our study took an experiential approach to learning, actively embracing new challenges and responsibilities to gain enhanced skills, knowledge, and confidence. As Participant B stated, this is because the librarian profession "is continuously evolving. I think we're a little bit more adaptable and willing to... be autodidactic and self-teach." This willingness to adapt and take on new responsibilities had a direct impact on transforming their roles as librarians:

I do feel like I learned through the practice; I learned through what I did in the project... For example, academic writing in history ...I don't feel very confident in that...that's something, you know, missing in my skills, but you know, by participating in this project, I feel I learned a lot through it. (Participant A)

Many of our interview participants also spoke to how their involvement had a direct impact on their traditional duties, including their exchanges at the reference desk and in library instruction:

I pass on the information... When you get involved in the research project and know how people work on that [the research], how they trained the PhD student... the whole process makes more sense for my reference service. (Participant A) 
Several participants stated that their participation in faculty research projects inspired them to pursue further higher education, such as doctoral studies in LIS or a related discipline. One participant felt this was a validation of the librarian role and that "the more people we have with MAs and PhDs, the better, because they are able to work more closely with the faculty." (Participant $\mathrm{H}$ )

\section{Adaptive Risk Taking}

All of the librarians we interviewed accepted new challenges and opportunities that fell outside the scope of their assigned roles and responsibilities. This strength made their participation on the research team vitally important:

What I bring to the discussion is the perspective of people who have been in other places. And so I can sort of step back and look at the situation in a way that some of my colleagues [Faculty] cannot... It's the kind of adaptability [that] makes [librarians] core key members of research teams...They're like the fluid that moves [laughs].(Participant C)

A consistent hallmark of our study was our participants' willingness to learn and adapt, knowing the possible risks that are involved: “I'm open to learning new things. I've learned what I've had to do and I'm not afraid to try to find out with something I don't know." (Participant C)

\section{Overcoming Challenges}

Some of the participants discussed the challenges arising from their research involvement. This primarily related to balancing workload:

I do find it hard sometimes in my daily life to pull away enough from the rest of the stuff that I do ...to use your brain in that research kind of way, so I end up bringing that home or doing it on a day when I'm here on a Saturday...I have a very hard time turning someone away who comes to my door that needs help... so definitely it can be tough to balance. (Participant D)

Another challenge that several participants mentioned is the set of preconceptions that sometimes exist about the professional identity of "the librarian" and the perceived abilities on a research project:

It's a very fine line sometimes between the support role that we have as librarians and research partner[s]... I encourage... librarians to walk very carefully to not be handmaidens to the faculty, but often that's initially what the researchers are expecting... It's largely about negotiation, it's about input and it's about setting some boundaries. (Participant F)

Finally, several participants expressed dissatisfaction with the lack of a methodological foundation within the LIS discipline. As a result, librarians felt they had to participate in faculty research projects instead of undertaking their own research:

We don't tend to structure ourselves or think of ourselves as independent researchers. We tend to think of ourselves, in our discipline and domain, as being structure and support for researchers...Our literature doesn't privilege formal research...We are truly interdisciplinary, and we sort of feel like we're second-class citizens when we're borrowing from other disciplines because we don't have our own methodology. (Participant F) 


\section{Conclusion and Future Directions}

Our exploratory research study has highlighted the experiences and learning of Canadian academic librarians who have been embedded in faculty research projects. The qualitative approach to our study has allowed us to engage deeply with the experiences and narratives of our research participants. Erickson confirms this, noting that qualitative inquiry "seeks to discover and to describe in narrative reporting what particular people do in their everyday lives and what their actions mean to them." ${ }^{28}$ The intent of our study was not to find statistically significant correlations that can be applied in general to the Canadian academic librarian population. Instead, we hoped to create rich and meaningful descriptions of the interactions and experiences of our participants. These stories offer users new narratives that can be applied within the context of librarian research simply by the virtue of the insight they provide to readers. ${ }^{29}$ In addition, the narratives reveal themes that may support future action and also inspire more librarians to think about engaging with a faculty member as a partner in a research process.

Our study also extends the existing literature regarding the transformation that is occurring in the role of Canadian academic librarians. While participants indicated that the role of librarians is expanding beyond traditional boundaries, we hope our findings provide concrete examples of ways for librarians to engage in a collaborative partnership or, if approached, to feel confident about taking such a risk. We also hope these findings will encourage librarians to consider leading their own research project or to become the primary investigator in a research collaboration.

As Janke and Rush point out, librarians are no longer peripheral in academic research but are now full members of investigative teams. ${ }^{30}$ But, as our research findings have highlighted, they are making this transition as a result of prior relationships with faculty brought about through traditional liaison work involving collection development, acquisitions, and information-literacy instruction. As our data demonstrates, the extent to which our participants were engaged within all aspects of the research process supports our starting belief that librarians have a vital and important contribution to make in redefining the role of the librarian in higher education.

To enhance this area of qualitative research, the study of faculty perspectives on librarians as collaborative research partners could be a beneficial contribution to the evolving landscape of the profession in Canada. By extension, the research experiences of librarians working in specific disciplines, focusing exclusively on either the sciences or the humanities, would provide a greater understanding of the capacity and learning of librarians in these research disciplines. Furthermore, as one of our participants expressed, there are perceptions of librarians as "handmaidens" to faculty, raising important questions about professional identity and gender that are core to librarianship and deserving of further study. These types of research would both complement and extend the librarian perspectives identified in our study and provide further analysis of how the professional identity of librarians is being redefined by their involvement in research projects. 


\section{APPENDIX. Interview Questions}

1. How long have you worked as an academic librarian?

2. Did you learn research methodologies when you were doing your MLIS?

3. Did you expect to be doing research when you graduated with your Master's degree?

4. Are you expected to undertake research as part of your job?

5. How did you get involved in campus research projects? Explain.

6. What was your role in the research projects? Explain.

7. Did you feel you had adequate education, training, and research skills-either through your education or work experience-to undertake your assigned role on the research project? Were there any gaps in this knowledge?

8. What did you feel were your professional strengths in the research project?

9. What skills and abilities did you feel were learned or enhanced as a result of being involved in the research project?

10. What unique contribution(s) and/or expertise as an academic librarian did you think you brought to the research project that no other faculty and/or researcher could fulfill?

11. Did you work within a research agenda set by your library and/or institution?

12. Did your participation in the research project relate to your own research interests? Explain.

13. How was your role as a researcher perceived by peers, faculty, other researchers, and the administration? Explain.

14. How did your research contribute to the field of LIS?

15. Was being involved in this research project worth it? What was the value?

16. Is there anything else significant about your experience that you would like to share?

\section{Notes}

1. The New Academic Librarian: Essays on Changing Roles and Responsibilities, eds. Rebecca Peacock and Jill Wurm (Jefferson, N.C.: McFaraland \& Co., 2013).

2. Simon Marginson, "Dynamics of National and Global Competition in Higher Education," Higher Education 52, no. 1 (2006): 1-39.

3. See, for example, R. Rayman and F.W. Goudy, "Research and Publication Requirements in University Libraries," College \& Research Libraries 41, no. 1 (1980): 43-48; Betsy Park and Robert Riggs, "Tenure and Promotion: A Study of Practices by Institutional Type," Journal of Academic Librarianship 19, no. 2 (1993): 72-77; Joyce Payne and Janet Wagner, "Librarians, Publication, and Tenure (Research Note)," College \& Research Libraries 45, no. 2 (1984): 133-39.

4. Rayman and Goudy, "Research and Publication Requirements in University Libraries"; see also John Cosgriff and Donald Kenney, "Support for Publishing at Academic Libraries: How Much?" Journal of Academic Librarianship 16, no. 2 (1990); and W.M. Havener and W.A. Stolt, "The Professional Development Activities of Academic Librarians: Does Institutional Support Make a Difference?" College E Research Libraries 55, no. 1 (Jan. 1, 1994): 25-36.

5. For example, S.A. Berg, H.L. Jacobs, and D. Cornwall, "Academic Librarians and Research: A Study of Canadian Library Administrator Perspectives," College \& Research Libraries 74, no. 6 (2012): 560-72.

6. Zara Wilkinson, "Rock around the (Tenure) Clock: Research Strategies for New Academic Librarians," New Library World 114, no. 1/2 (Jan. 4, 2013): 54-66.

7. Ronald R. Powell, Lynda M. Baker, and Joseph J. Mika, "Library and Information Science Practitioners and Research," Library \& Information Science Research 24, no. 1 (2002): 49-72.

8. Ibid., 50.

9. David Fox, "Finding Time for Scholarship: A Survey of Canadian Research University Librarians," portal: Libraries and the Academy 7, no. 4 (2007): 451-62.

10. Ibid., 452.

11. Rebecca Watson-Boone, "Academic Librarians as Practitioner-Researchers," Journal of Academic Librarianship 26, no. 2 (2000): 85-93.

12. Ibid., 85.

13. M.R. Kennedy and K.R. Brancolini, "Academic Librarian Research: A Survey of Attitudes, 
Involvement, and Perceived Capabilities," College \& Research Libraries 73, no. 5 (2011): 431-48.

14. David Schumaker, "Succeeding with Embedded Librarianship," Information Outlook 15, no. 4 (2011): 2.

15. Ibid., 4 .

16. See Claire McGuinness, "Exploring Strategies for Integrated Information Literacy: From 'Academic Champions' to Institution-Wide Change," Communications in Information Literacy 7, no. 2 (2007): 26-38; Gisela Butera, Alexandra W. Gomes, and Seema Kakar, "Expanding Our Roles: Embedded in Curriculum Design," Medical Reference Services Quarterly 33, no. 3 (2014): 292-301; Swapna Kumar and Mary E. Edwards, "Information Literacy and Embedded Librarianship in an Online Graduate Programme," Journal of Information Literacy 7, no. 1 (2013); and Mary E. Edwards and Erik W. Black, "Contemporary Instructor-Librarian Collaboration: A Case Study of an Online Embedded Librarian Implementation," Journal of Library \& Information Services in Distance Learning 6, no. 3/4 (2012): 284-311.

17. See Kathy Drewes and Nadine Hoffman, "Academic Embedded Librarianship: An Introduction," Public Services Quarterly 6, no. 2/3 (2010): 75-82; Jake Carlson and Ruth Kneale, “Embedded Librarianship in the Research Context," College \& Research Libraries News 72, no. 3 (2011): 167-70.

18. See Carlson and Kneale, "Embedded Librarianship in the Research Context"; Clare McCluskey, "Being an Embedded Research Librarian: Supporting Research by Being a Researcher," Journal of Information Literacy 7, no. 2 (2013): 4-14; Jeffrey A. Knapp, Nicholas J. Rowland, and Eric P. Charles, "Retaining Students by Embedding Librarians into Undergraduate Research Experiences," Reference Services Review 42, no. 1 (2014): 129-47.

19. Carlson and Kneale, "Embedded Librarianship in the Research Context," 167.

20. Herbert J. Rubin and Irene S. Rubin, Qualitative Interviewing: The Art of Hearing Data (Thousand Oaks, Calif.: SAGE Publications, 1995).

21. John W. Creswell, Qualitative Inquiry and Research Design: Choosing Among Five Approaches, 3rd ed. (Los Angeles: SAGE Publications, 2012).

22. Sharan B. Merriam, Qualitative Research: A Guide to Design and Implementation (San Francisco: Jossey-Bass, 2009).

23. Kenning Arlitsch, "Committing to Research: Librarians and Grantsmanship," Journal of Library Administration 53, no. 5/6 (2013): 369-79.

24. A.M. Schrader, A. Shiri, and V. Williamson, "Assessment of the Research Learning Needs of University of Saskatchewan Librarians: A Case Study," College \& Research Libraries 73, no. 2 (2011): 147-63.

25. Lars Christiansen, Mindy Stombler, and Lyn Thaxton, "A Report on Librarian-Faculty Relations from a Sociological Perspective," Journal of Academic Librarianship 30, no. 2 (2004): 118.

26. Core Competencies for 21st Century CARL Librarians (Ottawa: Canadian Association of Research Libraries, 2010), 9.

27. Kennedy and Brancolini, "Academic Librarian Research," 438.

28. Frederick Eriksen, "A History of Qualitative Inquiry in Social and Educational Research," in The Sage Handbook of Qualitative Research, 4th ed., eds. Norman K. Denzin and Yvonna S. Lincoln (Thousand Oaks, Calif.: SAGE Publications, 2011), 43-59.

29. Merriam, Qualitative Research: A Guide to Design and Implementation.

30. Robert Janke and Kathy L. Rush, "The Academic Librarian as Co-Investigator on an Interprofessional Primary Research Team: A Case Study," Health Information \& Libraries Journal 31, no. 2 (2014): 116-22. 